\section{Original} Article

\begin{tabular}{|l|}
\hline Access this article online \\
hebsite: \\
http://ajobe.journals.ac.za/ \\
http://dx.doi.org/10.15249/6-1-11 \\
Quick Response Code: \\
\hline
\end{tabular}

Address for correspondence: Dr. Theo $\mathrm{H}$ Veldsman, Department of Industrial Psychology and People Management, University of Johannesburg, P.O. Box 524, Auckland Park 2006, Johannesburg, South Africa. E-mail: theov@uj.ac.za

\title{
The soft underbelly of corporate governance (Part 2): The software of board dynamics
}

\author{
Theo H. Veldsman
}

Department of Industrial Psychology and People Management, University of Johannesburg, South Africa

\section{ABSTRACT}

In spite of the abundance of corporate governance codes, legislation to ensure compliance, and stock exchange reporting requirements, corporate failures still persist because of poor governance. It can be argued that though the 'rules of the road' - codes, legislation, and requirements - are in place, the chances of governance failure will remain high if explicit attention is not given to 'soft' governance: the "black box of what happens behind the boardroom door in terms of board dynamics. The relatively unstudied people side of boards remains the soft underbelly of corporate governance, its Achilles heel. The aim of this two-part paper is to address the elements affecting board dynamics and board performance, together with the consequential implications for corporate governance. A conceptual framework for soft governance is proposed by means of which board dynamics and performance can be explored and studied. This is Part 2 of the two-part article.

Key words: Board dynamics, Board performance, Board effectiveness, Corporate governance, Soft governance

\section{ORIENTATION}

The purpose of this two-part article is to explore the factors affecting and contributing towards sound 'soft' corporate governance, the spirit of the content and process of governance as affected by the people side of a board. The aim of the article is therefore to build an in-depth and comprehensive understanding of board dynamics, which is the soft underbelly of corporate governance, its Achilles heel. The article aims to propose a conceptual model of soft governance in terms of which board dynamics can be explored and understood.

The following topics are addressed in this article: firstly, the unique character of a board as a group that needs to become a team; secondly, a map of the 'performance space' of a board, which charts the elements of soft governance; and, thirdly, the specific elements of a board's performance space as seen from the vantage point of board dynamics.

Part 1 of this article addressed the unique character of a board as a group that has to become a team, the "performance space" of a board (Figure 1 in Part 1 of this article), and the 'hardware' of the board set-up (Figure 2 in Part 1 of this article). The hardware of the board set-up was described in Part 1 as the formal aspects of a board's functioning that define and frame a board's role and mode of working. Part 2 deals with the 'software' of the board set-up, the evolutionary life-cycle stages of board development, and board performance outcomes [Figure 2]. The software of the board set-up was defined in Part 1 as the process of working together as board members.

\section{THE BOARD SET-UP: ITS SOFTWARE}

Within the context provided by the hardware as the necessary conditions for the board set-up, the software of the board set-up encompasses the elements pertaining to board processes of the conditions that enable constructive and healthy board dynamics.

The software elements can be grouped into three types (Figure 2, Part 1):

- The macro software elements: These elements provide the overall framework for board processes. In contrast to the hardware elements, which provide the outer context of board dynamics, these elements provide the inner dynamic 
context in which the micro software elements are embedded (see below): The organisation's image and reputation, the dominant coalition on the board, and the culture and climate of the board;

- The micro software elements: These elements directly affect ongoing, daily board processes and include the leadership displayed within and by the board, personal engagement by board members, power usage by and politics within the board, as well as the interaction pattern between members; and

- Trust: As the resultant outcome of the interaction between all of the above software elements.

Though the hardware elements set the preconditions for the software elements of the board set-up, the software elements the board processes - can, conversely, strengthen or weaken the hardware elements, however well these have been set up (cf. Bain, 2008). Patterns of board process dynamics thus emerge, whether virtuous or vicious, affecting the board's soft governance (Huse, Minichilli and Shøning, 2005).

Each software element will be discussed in turn, moving from the macro elements through the micro elements to trust.

Macro software element 1: Organisational image Each and every organisation has a certain image (Figure 2) that gives it a certain reputation, whether good or bad, amongst its stakeholders and within its operating context (Pharoah, 2003). The reputation of the organisation will entice or repel individuals to make themselves available as prospective board members, which will affect the potential quality of members serving on the board. Conversely, board members, in a selffulfilling way, enact and live out the organisation's image and, hence, reinforce or undermine the organisation's reputation. Consequently, an organisation attracts the board members it deserves because of its image. In turn these board members reinforce the organisation's reputation.

In this way, a virtuous or vicious cycle is established in the two-way interaction between the organisation's image and reputation, and the quality of persons serving on its board. In the case of a virtuous cycle, a positive reputation results in the attraction of high-quality board members who, in turn, further enhance the reputation of the organisation, resulting in the attraction of even higher quality board members, and so forth. In the case of a vicious cycle, the opposite, downward spiralling dynamic occurs. Key elements of the image and the consequential reputation of a board are the core values and ethics stakeholders perceive the board to ascribe to, which, in turn, would influence their mode of interacting with the board.

\section{Macro software element 2: Dominant coalition on} the board

As discussed above, one of the unique features of a board as a team is that one becomes a board member through politically-based election (or even nomination), where board members are expected, whether explicitly expressed or not, to promote and serve the parochial interests of the stakeholders whom they represent (Van Ees, Gabrielsson and Huse, 2009). If a biased preference exists for board members with a certain profile, e.g. financial competence, sector expertise, or diversity (in terms of employment equity), a certain profile of board member may also be overrepresented on that board which would result in a certain way of looking at the world.

Virtually without exception, like-minded or parochial, interest-based board members coalesce spontaneously and/ or deliberately over time into a coalition [Figure 2]: A set of board members expressing closely aligned views/positions on board matters and pursuing common outcomes. If such a coalition is strong - whether in sheer numbers, because of the personal reputation and standing of the members, and/ or because of the standing they are awarded on the board because of their real/perceived backing by their sponsors outside the board - it will become the dominant coalition on the board (cf. Tricker, 2009).

If the dominant coalition has the superordinate interests of the organisation at heart, such a coalition will work to the benefit of the organisation within the framework set by the hardware elements, which, in the ideal situation, would have been established though a consensus-seeking process. However, if the dominant coalition is pursuing parochial interests and using the organisation as an instrument to drive and implement those interests, the scene has been set for a divided, conflict-ridden board. The board has now been hijacked by a set of members for their own purposes. Very often under these conditions, a counter-coalition emerges spontaneously in the board, even if its members are joining hands for the sole reason of opposing the 'common enemy' represented by the dominant coalition. Such a situation will cause the board to become increasingly dysfunctional.

Parochial, self-interest-seeking, dominant coalitions will furthermore frequently act as a barrier to consensus on the hardware elements of the board set-up. Or they will push through decisions on these elements in order to ensure that the elements act as conduits for their own interests. The affected board hardware elements will set the board up for failure since they will become bones of contention, poisoning board dynamics.

\section{Macro software element 3: Culture of the board}

The vantage point of the board, an aspect of the hardware element positioning (dealt with in Part 1 of the article) entails how the board views the world and the way it works. The culture of the board [Figure 2] refers to: (i) Its shared attitude of engaging with the board's work and (ii) its established style of doing things as a board - its rules of engagement. Figures 8 and 9 respectively present two 


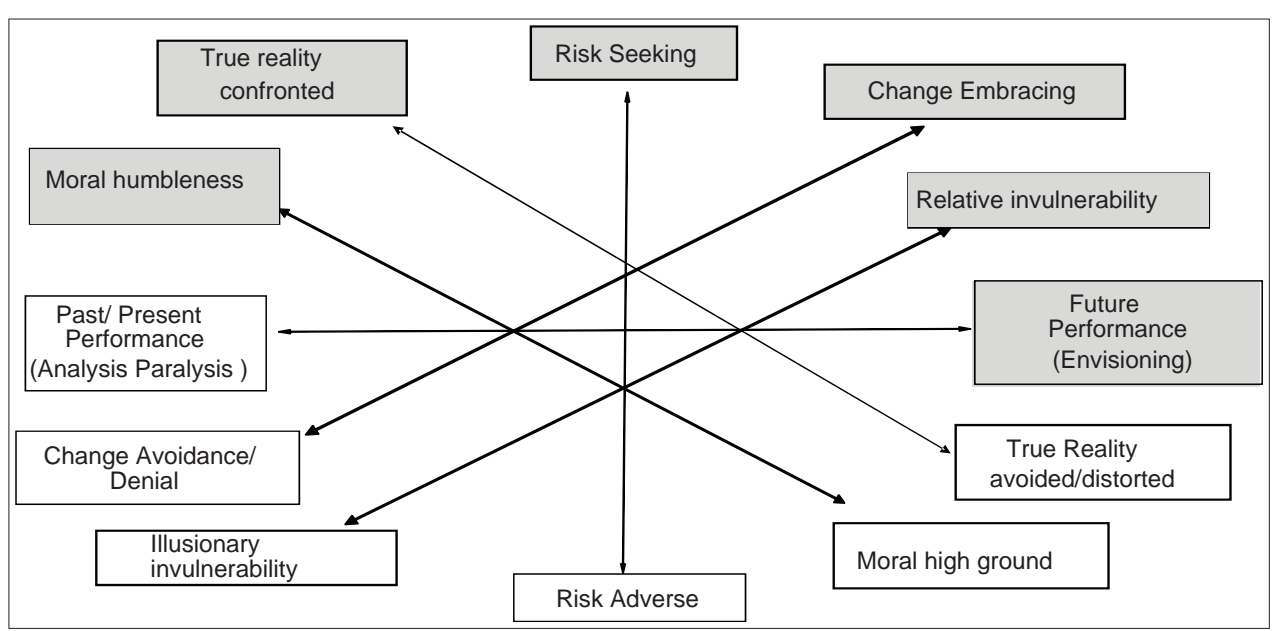

Figure 8: Possible shared board attitudes in engaging with the work of the board

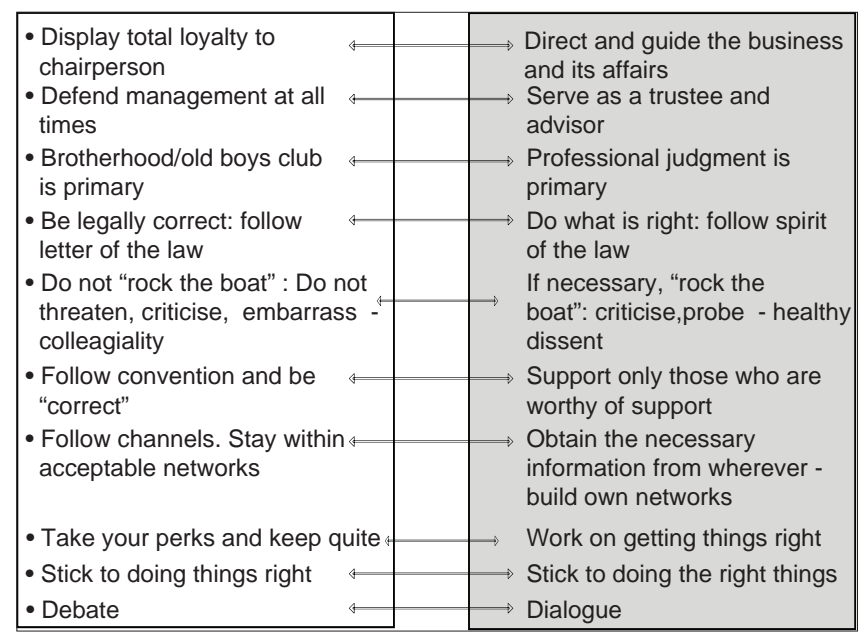

Figure 9: Possible shared styles of doing things in the board

contrasting sets of attitudes and style of doing things on a board (compiled by the author and based on Brountas, 2004, Charan, 2005; Garratt, 2003; Huse, Minichilli and Shøning, 2005; Nadler, Behan and Nadler, 2006; Minichilli, Zattoni and Zona, 2009; Naidoo, 2009; Petrovic, 2008; Tricker, 2009; Vandewaerde, Voordeckers, Lambrechts and Bammens, 2011).

The shaded boxes in the two figures indicate more progressive boards that are better aligned to the newly emerging world order, as sketched in the introduction in Part 1 of this article. Though covered separately, attitudes and style affect one another recursively, in this way creating the overall board culture.

In the case of constructive, healthy boards dynamics, leveraged from consensus on the hardware elements, a shared attitude and style - i.e. a strong common culture will readily emerge in the board. In the case of destructive and unhealthy board dynamics, no such culture will emerge. Significantly different and opposing attitudes and styles will be adopted by the board members. Hence, a weakly-shared or fragmented common culture will exist.

Such differing and opposing attitudes and styles need, however, not always be divisive. They may serve to engender a more balanced and rounded approach to the board business at hand, in this way preventing the emergence of groupthink in a board. These differences may also act as an important trigger and source of constructive conflict, reinvention, and creativity in the board. This will only be the case if a board holds an 'And,' and not an 'Either/ Or, view of the world (Figure 4 in Part 1). In the former view of the world, a dynamic balance will be sought and maintained between contrasting attitudes and styles in the board.

Additionally, the board culture validates, in a truly operational sense, the profile of members that have been selected to serve on the board. With reference to Figures 8 and 9, if a board has an 'unshaded' (or restrictive) instead of a 'shaded' (or progressive) culture, questioning, innovative, risk-seeking, and/ or maverick board members may view themselves as 'misfits and feel unwelcome. A board culture can liberate board members by establishing a shared attitude and style that frees them to act when they fit that culture. By the same token, a board culture can constrain its members by excluding different attitudes and styles, and in this way clone people who behave in a certain way, while those who feel that they do not fit in, depart (Veldsman, 2002). Over time, an increasing fit between the board's culture and the profile of its members may thus emerge.

\section{Macro software element 4: Climate in the board}

Whereas the board culture refers to shared attitudes and style amongst board members, the climate in the board deals with the prevailing mood (or vibe) that permeates the board's functioning and dynamics on an ongoing basis [Figure 2] (cf. Huse, Minichilli and Shøning, 2005; Vandewaerde, Voordeckers, Lambrechts and Bammens, 2011). 
Figure 10 offers two contrasting prevailing moods that may be present in a board (cf. Garratt, 2003; Huse, Minichilli and Shøning, 2005). The descriptors in the shaded box indicate the mood that is conducive to a teaming atmosphere, reflective of a psychosocial contract of partnering/identification amongst board members and, hence, to constructive and healthy board dynamics. Descriptors in the unshaded box indicate an opposing mood in terms of board dynamics: a conflictive, oppressive and compliant mood.

Progressively, over time, the ruling culture and climate in the board will become mutually re-enforcing. An enabling board culture and climate (Figures 8, 9, and 10) will enable constructive board dynamics and contribute towards sound corporate governance. A disabling board culture and climate (unshaded in the same figures) create a breeding ground for divisive, destructive board dynamics and, hence, the breeding ground of poor corporate governance.

\section{Micro software element 5: Leadership}

A multitude of definitions of leadership exist. For the purpose of this article, leadership is defined as acts of influencing aimed at directing and guiding a group of people, in this case board members, to collectively pursue a shared agenda and goal(s) in order to achieve desired, shared outcomes (Bain, 2008; Northouse, 2007; Veldsman, 2002). Every board has, either implicitly or explicitly, a leadership stance - a perspective on how leadership should be viewed and exercised in and by the board - especially since many, if not all, the board members will be in senior leadership positions outside of the board (Figure 2) (Bain, 2008; Charan, 2005; Conger, Lawler and Finegold, 2001; Garratt, 2003; Huse, Minichilli and Shøning, 2005; Nadler, Behan and Nadler, 2006; Tricker, 2009).

A board's leadership stance can be plotted in three dimensions:

- Focus: What is the underlying, central theme of the board's leadership intent? Three foci are possible:

(i) Transactional ("enhancing the existing"), (ii) transformational ("turning the existing into something

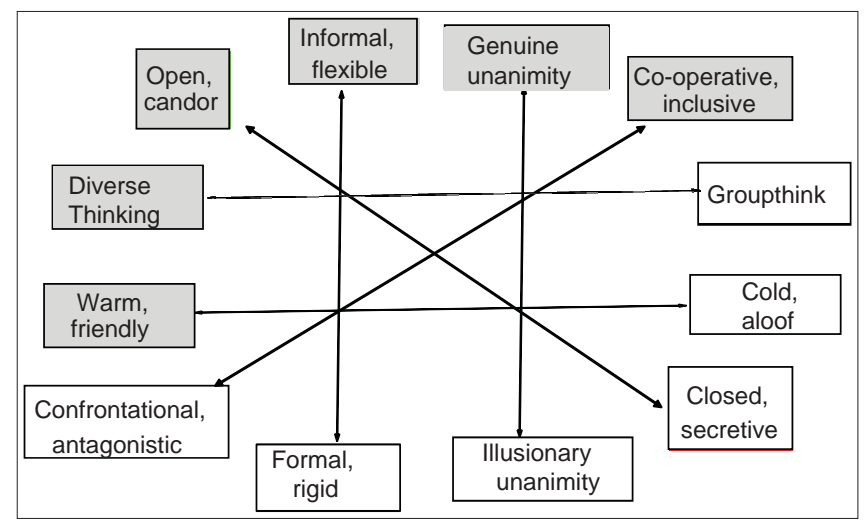

Figure 10: Possible contrasting prevailing moods in a board new and/or bringing the new into being"), and/or (iii) transcendental (or servant or steward) ("pursuing a worthy, meaningful cause; building a lasting legacy") (Northouse, 2007). A board's leadership usually has a primary focus, with the other two foci being secondary.

- Style: The freedom given by the chairperson to board members to act independently. In other words, the degree of autonomy board members are afforded. The range of possible styles in terms of relative autonomy is depicted in Figure 11.

- Mode: The manner in which leadership exerts its influence within the board. At least four modes are possible (cf. Northouse, 2007; Bennis, Spreitzer and Cummings, 2001): (i) A caretaking mode - influencing board members to believe that the 'good old days' are still the best and that things should be kept as they are, (ii) a crisis/paranoid mode - influencing members to perform by mobilising them to respond to ongoing crises, whether real and/or artificially created, (iii) an instrumental mode - influencing members by establishing clear links between efforts, goals, outcomes, and rewards/recognition, and (iv) a visionary/ purpose-driven mode - influencing members' actions through the building and actualisation of a shared, inspiring vision/cause that will contribute to leaving a lasting legacy. Similar to focus, a primary mode of leadership will be active in a board, with the other modes being secondary, to a greater or lesser extent.

A board's leadership stance is therefore a mixture of focus, style, and mode. There is no right or wrong leadership stance, assuming that the board, at all times, acts ethically. Each and every board must deliberately choose and act in accordance with its own leadership stance. Nowadays, there is a general shift towards leadership demonstrating a predominantly transcendental/transformational focus, a co-determination style, and a visionary/purpose-driven mode of leadership in a world typified by accelerating, radical, and discontinuous change, blossoming diversity, bewildering ambiguity, increasing complexity, heightened interdependency, and increasing boundarilessness, as was outlined in the introduction to Part 1 of the article (cf. Northouse, 2007; Bennis, Spreitzer and Cummings, 2001).

It can thus be argued that a board, in providing overall leadership to the organisations it oversees, should adopt a similar leadership stance. In turn, the chosen leadership stance of the board, whether explicitly or implicitly adopted, will affect the board's culture and climate. The leadership

\begin{tabular}{|c|c|c|c|c|}
\hline $\begin{array}{l}\text { Self } \\
\text { govern }\end{array}$ & Co-determine & Consult & Sell & Tell \\
\hline $\begin{array}{l}\text { Board members' } \\
\text { autonomy }\end{array}$ & & \multicolumn{3}{|c|}{$\begin{array}{l}\text { Chairperson's } \\
\text { autonomy }\end{array}$} \\
\hline
\end{tabular}

Figure 11: Range of possible leadership styles 
stance of a board will also have an important bearing on the board's image and, thus, its reputation.

\section{Micro software element 6: Personal engagement}

A board is made up of people who participate as complete persons in the affairs that board, ideally having been elected/nominated to serve in terms of an upfront, agreed-upon competency profile, as discussed in Part 1 of the article. Thus, present in the boardroom would be the sum total of board members' 'givens' (e.g. aptitudes, gender, race, personality, and temperament), life histories, acculturalisation or social programming (e.g. value and belief systems) (cf. Chan and Cheung, 2008), personal and interpersonal styles and attitudes, expertise/knowledge, track records, as well as personal standing and reputations. All of the aforementioned form the basis of the preferred roles that board members wish to, and do, play in the board, and hence constitute the make-up of the board terms of its actual individual members (Bain, 2008; Huse, Minichilli and Shøning, 2005) [Figure 2].

If board members have been elected/nominated in terms of a board competency profile at both an individual and board level through a thorough process, the 'right' people will be in the boardroom, but they will be strangers to one another. The challenge is to transform this group of strangers into an effective team of trusted partners, invoking the right chemistry in light of the unique features of a board as a team, as explicated in Part 1 of the article. In particular considering the low frequency of their face-toface interaction.

To this end, a deliberate, ongoing process has to be put in place to build simultaneously increasing levels of understanding - the factual knowledge members have of each other - and acceptance of each other - the emotional bonding of members with one another in terms of who and what they are as persons. Without such a process, the chances of destructive and unhealthy board dynamics may be significantly increased, causing board members to operate like ships passing in the night, strangers remaining strangers.

Concurrently, the competencies present in the boardroom may also then be significantly underutilised and incorrectly deployed because board members do not know and/or accept one another. This may cause significant personal frustration for individual members.

\section{Micro software element 7: Power and politics}

Power and politics are part and parcel of a board and its dynamics (Tricker, 2009) [Figure 2]. At issue is how and to what end the power and politics present in a board are applied: towards the common good of the board and the organisation concerned with its stakeholders or towards personal and/or parochial interests? The question is whether the board's use of its power with the associated politics is leveraged from an ethical, corporate citizen basis or a purely expedient, opportunistic, and self-serving basis (Davis, Schoorman and Donaldson, 1997; Garratt, 2003; Van Ees, Gabrielsson and Huse, 2009). The presence of a dominant coalition or not also can play a significant role in his power is deployed, and politics unfold in a board. If constructively addressed, the hardware and software elements will substantially increase the probability of power and politics in the board being used ethically and positively in the interest of the common good.

By its very nature, a board is a body with authority, implying that it has certain powers at its disposal. Thus, members have power, in the first instance, by virtue of their membership of the board. With this power comes certain responsibilities and privileges, but also obligations. Often, board privileges receive the most attention, with responsibilities and obligations being poor, distant cousins, resulting in so-called 'fat cat' or 'entitlement' boards. Tensions regarding the proper balancing of responsibilities, obligations, and privileges may further contribute to destructive board dynamics. The way in which this tension is resolved may result in a certain board image and reputation amongst its stakeholders; as has been discussed above. It may also lead to the attraction of certain types of board members. Reputable, ethics-driven boards are able to maintain a fine balance between responsibilities, obligations, and privileges.

At a personal level, board members derive their power in the board from one or more sources: Their personal charisma, reputation, expertise/knowledge; the role/position they hold on the board; their ownership share; and/or their membership of and role in a dominant coalition, if one is active within the board (cf. Garratt, 2003; Tricker, 2009). It can be argued that the more power sources a board member can mobilise, the more powerful that member will be. It is important for board members to have insight into the real source(s) of their power, and to honestly weigh the 'rightfulness' of their personal motivation regarding how and towards what ends they want to use their power in board politics. This assumes a high level of personal maturity, integrity, and honesty in board members.

\section{Micro software element 8: Interaction pattern}

As discussed in the section on the unique character of a board, a board need to exercises its authority as a team. Its power lies in its collective wisdom, which is released in a value-adding way only when the board functions effectively as a collective body - when the board speaks as one voice from many.

A critical enabling software element in the board's effective functioning as a collective body is the interaction pattern that becomes established and institutionalised in the board over time - the way in which board members work 
together in doing the board's work, both during and between board meetings [Figure 2] (Huse, 2009; Huse, Minichilli and Shøning, 2005; Marcus, 2008; Petrovic, 2008; Van Ees, Gabrielsson and Huse, 2009). This interaction pattern manifests in the set ways in which the board handles work processes such as information-gathering/ sharing, problem-solving, decision-making, and conflict resolution. In a sense, the interaction pattern in force in a board at any given time is the visible manifestation of all the above-mentioned software elements. Recursively, an institutionalised interaction pattern re-enforces these elements, again establishing either a virtuous or a vicious cycle of board dynamics.

Figure 12 depicts two contrasting interaction patterns (the shaded and the unshaded boxes), respectively, indicating positive and negative patterns, the former being conducive to constructive, healthy board dynamics (cf. Huse, 2009; Huse, Minichilli and Shøning, 2005; Marcus, 2008; Petrovic, 2008; Van Ees, Gabrielsson and Huse, 2009).

\section{Micro software element 9: Trust}

For the purpose of this article, trust can be defined as positive expectations about others' motives, intentions and conduct, progressively validated over time.Mighoree De Cloucth 2011. From one angle, trust is the final outcome of the positive, constructive interaction of all of the above software elements. Trust, therefore, is the ultimate result of constructive and healthy board dynamics.

From another angle, trust or, more correctly, increasing levels of trust, acts as probably the most critical enabler in creating the conducive conditions under which the software elements can flourish in a sustainable manner. When issues arise with respect to any of the software elements, they can be successfully and permanently resolved because of the level of trust present (hence the central position of trust amongst all of the software elements in Figure 2). Trust is pivotal in engendering and maintaining constructive and healthy board dynamics (Bain, 2008; Huse, Minichilli and Shøning, 2005; Migoliore e De Cloueth, 2011. Petrovic,

\begin{tabular}{|c|c|}
\hline $\begin{array}{l}\text { - Shared Goods/Intentions/ Frame } \\
\text { of Reference }\end{array}$ & $\begin{array}{l}\text { - Individual Goals/Intentions/Frame of } \\
\text { reference }\end{array}$ \\
\hline - Unobtrusive Chairperson/CEO & t• Forceful/imposing CEO/Chairperson \\
\hline $\begin{array}{l}\text { - Flexible, free-flowing, organic } \\
\text { mode of working ("Teaming") } \\
\text { - Real business done inside the } \\
\text { boardroom }\end{array}$ & $\begin{array}{l}\text { - Rigid, predictable, linear mode of } \\
\text { working ("Meeting") } \\
\cdot \text { Real business done outside the } \\
\text { boardroom }\end{array}$ \\
\hline $\begin{array}{l}\text { - Complementary, harmonious } \\
\text { relationships/contributions } \\
\text { (Team players) }\end{array}$ & $\begin{array}{l}\text { - Competitive, conflict-ridden } \\
\text { relationships/contributions } \\
\text { (Pima Donnas/ Lone Rangers) }\end{array}$ \\
\hline $\begin{array}{l}\text { - Decisions based on sufficient } \\
\text { consensus }\end{array}$ & - Decisions based on majority vote \\
\hline $\begin{array}{l}\text { - Ongoing action learning/ } \\
\text { teaching } \\
\text { - High/open information sharing }\end{array}$ & $\begin{array}{l}\text { - No/little action learning/teaching } \\
\text { - Little/selective information sharing }\end{array}$ \\
\hline $\begin{array}{l}\text { - High collective commitment to } \\
\text { decisions/actions and } \\
\text { consequences thereof }\end{array}$ & $\begin{array}{l}\text { - Low collective commitment to } \\
\text { decisions/actions and } \\
\text { consequences thereof }\end{array}$ \\
\hline
\end{tabular}

Figure 12: Contrasting board interaction patterns
2008; Tricker, 2009; Vandewaerde, Voordeckers, Lambrechts and Bammens, 2011).

Paradoxically, because trust is an outcome of board dynamics, it cannot be dealt with directly. A board should rather, through its leadership, deliberately encourage and institutionalise trust-engendering behaviour between board members. This will allow trust to germinate and thrive in the board as it carries on with its day-to-day business. Figure 13 depicts trust-engendering behaviours (in the shaded box) in contrast to trust-eroding behaviours (the unshaded box).

In summary: Whereas the hardware elements of the board set-up create the preconditions for the software elements to flourish, the software elements, in a sense, more directly act as levers in promoting constructive and healthy board dynamics [Figure 2]. However, conducive software elements recursively provide the leverage to put the hardware preconditions in place -thus, very much a chicken-and-egg situation.

This is the point at which the second important element of the board's performance space becomes most relevant, namely the evolutionary life-cycle stage of board development (the four quartered circles in Figure 1).

\section{THE EVOLUTIONARY LIFE-CYCLE STAGES OF BOARD DEVELOPMENT RELATIVE TO ITS TASK AND PROCESS PERFORMANCE AXES}

Without exception, groups (including boards) aspiring to transform themselves from merely a collection of individuals into a genuine high-performance team need to move through successive, evolutionary life-cycle stages of development (cf. Wheelan, 2005; Vandewaerde, Voordeckers, Lambrechts and Bammens, 2011). Only then will they be able to perform at the highest possible level and reinvent themselves as and when circumstances demand it.

The following principles apply to the evolutionary life-cycle

\begin{tabular}{|c|c|}
\hline $\begin{array}{l}\text { Promote common good } \\
\text { Accept questions and } \\
\text { contributions about their } \\
\text { personal responsibilities } \\
\text { Admit weakness and mistakes } \\
\text { Seek help and provide } \\
\text { constructive feedback } \\
\text { Give others the benefit of the } \\
\text { doubt before arriving at } \\
\text { negative conclusions } \\
\text { Appreciate and respect others } \\
\text { for who and what they are } \\
\text { Seek and accept responsibility } \\
\text { and accountability } \\
\text { Focus time and energy on the } \\
\text { game and its outcomes } \\
\text { Show high commitment to } \\
\text { decisions or actions - keep } \\
\text { promises } \\
\text { Offer and accept apologies } \\
\text { without hesitation } \\
\text { Seek out opportunities to be } \\
\text { with one another }\end{array}$ & $\begin{array}{l}\text { - Promote personal and/ or parochial } \\
\text { interests } \\
\text { - Reject questions and contributions } \\
\text { about their personal responsibilities } \\
\text { - Conceal weaknesses and mistakes } \\
\text { - Hesitate to offer help and provide } \\
\text { little/destructive feedback } \\
\text { - Jump to conclusions about others' } \\
\text { intentions without attempting to } \\
\text { clarify them } \\
\text { - Demean others for who and what } \\
\text { - Avey are } \\
\text { accound and shift responsibility and } \\
\text { - Play to the grand stand for spectator } \\
\text { value } \\
\text { - Show little commitment to decisions } \\
\text { or actions - break promises } \\
\text { - Hold grudges } \\
\text { - Avoid opportunities to interact }\end{array}$ \\
\hline
\end{tabular}

Figure 13: Trust-engendering vs. trust-eroding board behaviours 
stages of a board in its transformation from a group into a team (cf. Wheelan, 2005):

- Each developmental stage has a central challenge that has to be addressed, which is reflected in the name of that stage.

- Each developmental stage needs to deal with both the hardware and software elements of board set-up appropriate to that stage. This is necessary to enable the board as a group to progress simultaneously on both the task axis (getting the job done) and process performance axis (working together as individuals and a team) within that stage and onto the next stage.

- If the same degree of developmental progress is not made on both performance axes by simultaneously dealing with both hardware and software elements, a board cannot progress to the next developmental stage in overall performance. The neglect of one set of elements will be to the detriment of performance on that axis, which will, in turn, result in the performance on the other axis being overemphasised.

- Typically, most, if not all, the hardware and software elements need to be addressed progressively in successive developmental stages at deeper and/or more complex levels of understanding, and may even have to be reinvented.

- Developmental stages cannot be skipped - a board has to move through the stages sequentially. Boards may, however, move more slowly or more rapidly through these stages.

- A board may stagnate in a developmental stage and be unable, even with external assistance, to progress beyond that stage, due to, for example, an inflexible, dominant coalition unwilling to change its position on one or more hardware and/or software elements because of an ideological stance or a discredited chairperson unwilling to resign.

- A board may regress to an earlier developmental stage if a significant hardware and/or software element(s) changes or has to be revised. This may be the case in, for example, a revised/new positioning of the board, a change in the leadership of the board, a significant critical mass of new board members (usually about one third), or a major trust-eroding event.

As can be seen from Figure 1, five successive, evolutionary life-cycle stages can be distinguished:

- Stage 1 - Forming: The central challenge of this developmental stage is to get a board up and running with respect to the task it has to perform, and for members to understand and accept one another personally as board members. During this stage, which is leader-led, the chairperson of the board needs to put in place the necessary basics regarding the hardware and software elements.

- Stage 2 - Storming: In this developmental stage, the central challenge is to create conditions under which board members feel free to start challenging the appropriateness of the Stage 1, leader-imposed hardware and software elements. For example, the board's direction, mode of working, leadership stance, and level of togetherness as a group.

- Stage 3-Norming: The challenge of this developmental stage is to debate, reach sufficient consensus, and roll out fit-for-purpose hardware and software elements that are appropriate to the unique character of the board concerned and the challenges it faces. During this stage, the board is intensively searching for and finding its own voice in all respects.

- Stage 4 - Performing: This developmental stage's challenge is to enable and empower the board to constructively and productively work together as a board. Having found its own voice regarding the elements, the board can now leverage its fit-for-purpose elements to make its own distinctive value-adding contributions to tasks and processes.

- Stage 5 - Re-inventing: In this developmental stage, the challenge is for the board to leapfrog to the next, higher and/or different level of performance, and also reach out to other boards. From the confidence in itself and the goodwill built amongst its stakeholders through its track record of consistently outstanding performance during Stage 4, the board will have earned the luxury to test the boundaries of the seemingly impossible and to experiment with respect to its institutionalised, proven hardware and software elements in order to arrive at completely new/different ways of operating as a board. Such a board will have truly become a learning board (Garratt, 1997; 2003), and will be able to explore and create futures never before conceived.

In summary, a board needs to understand and accept that it will not immediately perform efficiently and effectively at its maximum potential. A board has to undergo a deliberate and, if required, externally assisted process to move through successive stages of development to arrive at performance excellence. During this journey of increasingly higher levels of task and process performance, simultaneously holding both dimensions of performance in balance, the hardware and software elements of the board set-up have to be addressed time and again if a board wants to progress through the successive evolutionary stages of development. A board must also be alert to events that may cause it to regress to an earlier stage.

\section{BOARD PERFORMANCE OUTCOMES}

The performance outcomes of a board (the diagonal in Figure 1) are a function of the board's evolution, or not, through its life-cycle stages, and thus of its concurrent progress, or not, along the two performance axes of task and process.

Frequently, in the assessment of board performance 
outcomes, only adherence to the content of corporate governance codes - the rules of the game - is recommended in corporate governance codes. Metaphorically speaking: "Are we consistently driving on the right side of the road?" However, "How we are driving, even if we are on the right side of the road" is not assessed. It has been argued all along that, in order to deal with the soft underbelly of governance, both the content and process, as well as the letter and spirit of good governance must be addressed. In other words, all the elements contained in the performance space of the board, as per Figure 1, that affect board dynamics and, hence, its overall performance.

The view taken throughout this article is therefore also relevant in defining, tracking, and assessing the board's performance - the last element of the board's performance space. The comprehensive assessment of board performance allows one to complete the circle by indicating what needs to be changed or done differently in terms of the board set-up elements (cf. Nadler, Behan and Nadler, 2006).

A board's performance must be defined, tracked, and assessed in a holistic, integrated, and systemic manner. "Holistic" means having a complete set of measurement variables covering the total spectrum of the board's performance elements, which is the overall thrust of this article. "Integrated" refers to showing how the respective measurements group together logically in terms of board performance dimensions, i.e. viewing the board's performance multi-dimensionally. "Systemic" pertains to considering dynamically, in real time how the respective measurement dimensions with their associated metrics affect each other and, hence, overall board performance (cf. Garratt, 2003).

Figure 14, conceived by the author, gives a graphic view of a suggested board performance model with its various dimensions, using a Balanced Scorecard approach (Kaplan and Norton, 1992), in terms of which the performance of a board can be judged (see also Vandewaerde, Voordeckers, Lambrechts and Bammens, 2011). For each of the performance dimensions given in Figure 14, measurement metrics must be defined, benchmarks sourced, and goals set. Most corporate governance codes only deal with Dimension 2 (effective board functioning in terms of adherence to formal governance guidelines). Some attention is given to the hardware, but little, if any, attention is paid to the software of governance.

As illustrated in Figure 14, four board performance dimensions can be distinguished:

- Dimension 1: Thriving, sustainable organisation How is the organisation which the board is overseeing performing? Is the organisation a going concern? As a going concern, is the organisation thriving in terms of, for example its profitability, ROI, share price, and

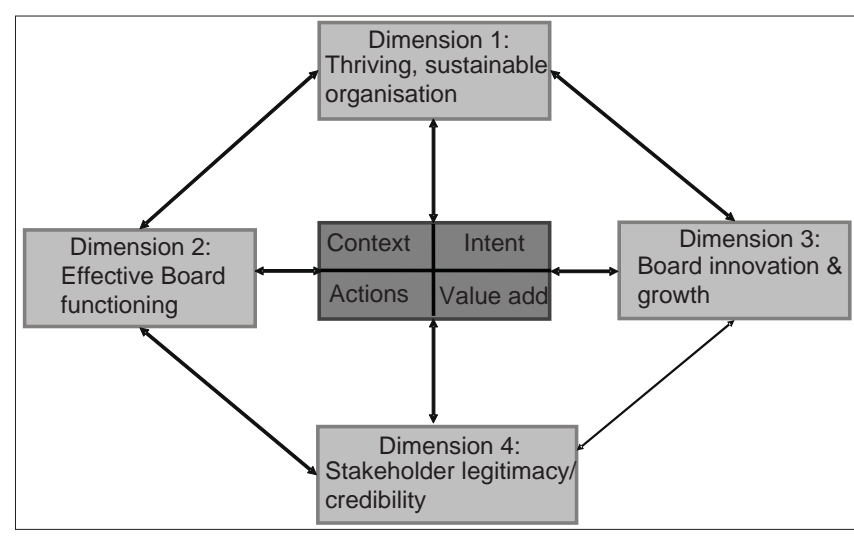

Figure 14: The board's performance dimensions

market capitalisation? This dimension addresses the raison d'être of the board - its formal designated role and tasks.

- Dimension 2: Effective board functioning - Is the board functioning well in terms of (i) adherence to generally accepted corporate governance guidelines, the typical assessment included in most corporate governance codes, (ii) the board dynamics as manifested in its hardware and software elements (The above discussion of the hardware and software elements provides guidance as to what could be assessed with respect to this measurement dimension), and (iii) the evolutionary life-cycle stage of development the board has reached? If the board has not yet achieved Stage 4, what must be done to advance the board to the stage of outstanding performance? This measurement dimension deals with the process and dynamics aspects of the board.

- Dimension 3: Board innovation and growth - Is the board learning from and reflecting on its current performance, as well as growing in its ability to excel as it moves into the future? Is the board investing in its own learning and development in order to proactively capacitate itself for future expected challenges and demands? This dimension covers at what rate the board is renewing and, if necessary, reinventing itself, relative to the rate and nature of change in its operating context. In other words, this dimension measures the extent to which the board has become a learning board (Garratt, 2003).

- Dimension 4: Stakeholder legitimacy/credibility What is the board's standing and stature amongst its stakeholders? Is the degree of goodwill the board has amongst its stakeholders broadening, deepening, and strengthening? This dimension addresses the extent to which the board can depend on the support and backing of its stakeholders in all endeavours undertaken by the organisation as it moves into an undefined and unpredictable future.

The board must have a deep and widely shared understanding 
of the dynamic interdependencies and linkages between the different board performance dimensions being tracked and assessed (the dynamic big picture). This insight needs to be used to direct and guide an ongoing dialogue about the board's performance and what actions need to be taken to bring about outstanding board performance. It is important to track and assess trends in terms of the measurement dimensions and metrics across time, and not to pay attention only to single measurements in isolation, e.g. only this quarter's or year's measurement.

Sufficient time at the right frequency must be set aside for the board to reflect on its performance in terms of its achievement on its performance dimensions, and to formulate an action plan to enhance its performance. Equal attention must be given to all the respective performance dimensions, as depicted in Figure 14, in the assessment and enhancement of the board's performance.

\section{CONCLUSION}

The purpose of this article was to explore the elements affecting and enabling sound soft corporate governance the people side of a board. It was the premise of this article that adherence to the spirit of corporate governance, or not, can be attributed to the dynamics between and amongst the directors of a board. Because little, if any, explicit attention is given to board dynamics in available codes and corporate governance literature, soft governance is at present the soft underbelly of corporate governance.

Within the context of the unique character of a board as a group that needs to become a team, a map of the performance space of the soft governance of a board was proposed. In other words, a conceptual framework was proposed through which the impact of board dynamics as soft governance can be explored and understood. The specific elements making up a board's performance space were discussed from the vantage point of board dynamics.

A deliberate, systematic process needs to be designed and implemented to conceive, design, plan, implement, and track the performance space elements of a board, as discussed in this article. If such a process is not followed, a board may be significantly vulnerable to the emergence of destructive and unhealthy board dynamics that could undermine compliance with the spirit of governance codes, the soft governance, which could detrimentally affect board performance. In this way, the scene will be set for significant corporate governance failures, regardless of how well a board is seemingly adhering to the letter, both in terms of content and process, of whatever corporate governance code it is following.

Ultimately, the effectiveness of a board contributes, in no uncertain terms, to the competitive edge and performance of the organisation it is overseeing (Charan, 2005; Chew and Gillian, 2005; Finegold, Benson and Hecht, 2007; Marcus, 2008; Payne, Benson and Finegold, 2009; Petrovic, 2008; Zona and Zattoni, 2007). By deliberately addressing soft governance, board effectiveness can be significantly enhanced. In this way, the chances of corporate failures because of poor soft governance may be significantly reduced.

\section{ACKNOWLEDGMENTS}

The valuable comments by the anonymous reviewers are gratefully acknowledged.

\section{REFERENCES}

Anderson, D.W., Melanson, S.J. and Maly, J. (2007). The evolution of corporate governance: Power distribution brings Boards to life. Corporate Governance, 15, 780-797.

Bain, N. (2008). The effective director. Building individual and Board success. London: Institute of Directors.

Barker, H.K. and Anderson, R. (2010). (Eds.). Corporate governance. A synthesis of theory, research and practice. New Jersey: John Wiley and Sons.

Bennis, W., Spreitzer, G.M. and Cummings, T.G. (2001). The future of leadership. San Francisco: Jossey-Bass.

Brountas, P.P. (2004). Board room excellence. San Francisco: Jossey-Bass. Chan, A.W.H. and Cheung, H.Y. (2008). Common cultural relationships in corporate governance across developed and emerging financial markets. Applied Psychology, 57, 225-245.

Charan, R. (2005). Boards that deliver. Advancing corporate governance from compliance to competitive advantage. San Francisco: Jossey-Bass. Chew, D.H. and Gillian, S.L. (2005). Corporate governance at the crossroads. Boston: McGraw-Hill Irwin.

Conger, J.A., Lawler, E.E. and Finegold, D.L. (2001). Corporate boards. Strategies for adding value at the top. San Francisco: Jossey-Bass.

Coulson-Thomas, C. (2009). Competencies of an effective director. Industrial and Commercial Training, 41(1), 27-35.

Curseu, P.L. (2009). Group dynamics and effectiveness: A primer. In S. Boros (Ed.). Exploring organizational dynamics. Los Angeles: Sage, 225-246.

Daily, C.M., Dalton, D.R. and Cannella, A. (2003). Corporate governance: Decades of dialogue and data. Academy of Management, 28, 371-382.

Davis, J.H., Schoorman, F.D. and Donaldson, L. (1997). Toward a stewardship theory of management. Academy of Management Review, 22, 20-47.

Finegold, D., Benson, G.S. and Hecht, D. (2007). Corporate boards and company performance: Review of research in light of recent reforms. Corporate Governance, 15, 865-878.

Fitzgerald, L.A. (2001). Chaos: The lens that transcends. Journal of Organizational Change Management, 15(4), 339-358.

Garratt, B. (2010). The fish rots from the head: The crisis in our Boardrooms. London: Harper Collins Publishers.

Garratt, B. (2003). Thin on the top. Why corporate governance matters and how to measure and improve Board performance. London: Nicholas Brealey Publishing.

Harrison, R. and Stokes, H. (1992). Diagnosing organizational culture. Amsterdam: Pfeiffer.

Huse, M., Minichilli, A. and Shøning, M. (2005). Corporate boards as assets for operating in the new Europe: The value of process-oriented boardroom dynamics. Organizational Dynamics, 34, 285-297.

Johnson, J.L., Ellsrand, A.E. and Daily, C.M. (1996). Boards of directors: A review and research agenda. Journal of Management, 22(3), 409-438. 
King Report on corporate governance for South Africa (King II). (2002). Johannesburg: Institute of Directors in Southern Africa.

King Report on corporate governance for South Africa (King III). (2009). Johannesburg: Institute of Directors in Southern Africa.

Lawler, E.E., Finegold, D.L., Benson, G.S. and Conger, J.A. (2002). Corporate Boards: keys to effectiveness. Organizational Dynamics, 30(4), 310-324.

Kaplan, R.S. and Norton, D.P. (1992). The balanced scorecard - measures that drive performance. Harvard Business Review, January-February, 71-79.

Leblanc, R. and Schwartz, M.S. (2007). The black box of board process: Gaining access to a difficult subject. Corporate Governance, 15, 843-851. MacAvoy, P.W. and Millstein, I.M. (2003). The recurrent crisis in corporate governance. New York: Palgrave Macmillan.

Mallin, C.A. (2010). Corporate governance. Oxford: Oxford University Press.

Marcus, M. (2008). Board capability. An interactions perspective on Boards of Directors and Firm performance. International Studies of Management and Organization, 38, 98-116.

McKinsey Investor Opinion Survey. (2002). New York: McKinsey.

McNulty, T. and Pettigrew, A. (1999). Strategists on the board. Organizational Studies, 20, 47-74.

Migliores, L-A and DeClouette, A.H. (2011). Perceptions of trust in the boardroom: A conceptual model. Journal of leadership and Organisational Studies, 18(3), 320-333.

Minichilli, A., Zattoni, A. and Zona, F. (2009). Making Boards effective: An empirical examination of Board task performance. British Journal of Management, 20, 55-74.

Murphy, S.A. and McIntyre, M.L. (2007). Board of director performance: A group dynamics perspective. Corporate Governance, 7(2), 209-224.

Nadler, D.A. (2004). Building better boards. Harvard Business Review, 82(5), 102-111.

Nadler, D.A., Behan, B.A. and Nadler, M. (2006). Building better Boards. A blueprint for effective governance. San Francisco: Jossey-Bass.

Naidoo, R. (2009). Corporate governance. As essential guide for South African companies. Durban: LexisNexis.

Northouse, P.G. (2007). Leadership: Theory and practice. Thousand Oaks: Sage.

Payne, G.T., Benson, G.S. and Finegold, D.L. (2009). Corporate board attributes, team effectiveness and financial performance. Journal of Management Studies, 46(4), 704-731.

Petrovic, J. (2008). Unlocking the role of a board director: A review of the literature. Management Decision, 46, 1373-1392.

Pharoah, A. (2003). Corporate reputation: The boardroom challenge. Corporate Governance, 3, 46-51.

Rezaee, Z. (2009). Corporate governance and ethics. New Jersey: John Wiley and Sons.

Snowden, D.J. and Boone, M.E. (2007). A leaders' framework for decision making. Harvard Business Review, November 2007, 1-8.

Stacey, R.D., Griffin, D. and Shaw, P. (2000). Complexity and management. Fad or radical challenge to systems thinking? London: Routledge.

Tricker, B. (2009). Corporate governance. Principles, policies and practices. Oxford: Oxford University Press.

Vandewaerde, M., Voordeckers, W., Lambrechts, F. and Bammens, Y. (2011). The board of directors as a team: Getting inside the black box. Proceedings of the $7^{\text {th }}$ European Conference on management, leadership and governance. Sophia-Antipolis, France, 436-442.

Van Ees, H. Gabrielsson, J. and Huse, M. (2009). Toward a behavioral theory of Boards and corporate governance. Corporate Governance: An International Review, 17(3), 307-319.

Veldsman, T.H. (2002). Into the people effectiveness arena. Navigating between chaos and order. Johannesburg: Knowledge Resources.

Veldsman, T.H. (2008). People management in the new order. In pursuit of leading world class practices (Part 1). Management Today, 28(8), 56-60.

Wheatley, M.J. (2006). Leadership and the new science. San Francisco: Berrett-Koehler.

Wheelan, S.A. (2005). Group processes. A developmental perspective. Boston: Allyn and Bacon.

Wixley, T. and Everingham, G. (2005). Corporate governance. Claremont: Siber Ink.

Zona, F. and Zattoni, A. (2007). Beyond the black box of demography: Board processes and task effectiveness within Italian firms. Corporate Governance, 15, 852-864.

How to cite this article: Veldsman $\mathrm{TH}$. The soft underbelly of corporate governance (Part 2): The software of board dynamics. Afr J Bus Ethics 2012;6:65-74.

Source of Support: Nil, Conflict of Interest: None declared

\section{AUTHOR}

Theo has extensive research and development, as well as consulting experience, gained over the past 25 years, in strategy formulation and implementation, strategic organisational change, organisational (re)design, team building, leadership/management development, and strategic people management. He is the author of about 180 reports/articles and authored a book titled "Into the People Effectiveness Arena - Navigating between chaos and order." He has also contributed eight book chapters on, respectively, organisational culture, organisational change interventions, strategic talent management, organisational partnering, learning and development leading practices, people competencies, the people professional in emerging countries, and the meta-theory of industrial and organisational psychology.

Announcement

\section{“QUICK RESPONSE CODE” LINK FOR FULL TEXT ARTICLES}

The journal issue has a unique new feature for reaching to the journal's website without typing a single letter. Each article on its first page has a "Quick Response Code". Using any mobile or other hand-held device with camera and GPRS/other internet source, one can reach to the full text of that particular article on the journal's website. Start a QR-code reading software (see list of free applications from http://tinyurl.com/yzlh2tc) and point the camera to the QR-code printed in the journal. It will automatically take you to the HTML full text of that article. One can also use a desktop or laptop with web camera for similar functionality. See http://tinyurl.com/2bw7fn3 or http://tinyurl.com/3ysr3me for the free applications. 
Reproduced with permission of the copyright owner. Further reproduction prohibited without permission. 